\title{
An irregular atrial tachycardia
}

\section{What is the underlying mechanism?}

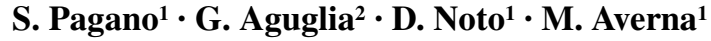

Published online: 27 October 2017

(C) The Author(s) 2017. This article is an open access publication.

A 66-year-old male patient with a history of rheumatoid arthritis, coronary artery disease, hypothyroidism, end-stage renal disease and receiving haemodialysis presented to the emergency department with palpitations. His medication was acetylsalicylic acid, pantoprazole, levothyroxine, and paracetamol and ibuprofen as needed. Laboratory test results showed a mild anaemia and serum potassium levels within the upper limit of normal. A 12-lead electrocardiogram was recorded (Fig. 1). The electrocardiogram shows narrow QRS complexes (0.08 sec) with a QS morphology in leads V1 through V4 consistent with an old antero-septal wall myocardial infarction. The rhythm is irregular at an average rate of 79 beats per minute with groups of beatings separated by pauses. However, the underlying rhythm is not a sinus rhythm.

\section{Question}

What is the mechanism?

\begin{abstract}
Answer
You will find the answer elsewhere in this issue.

Open Access This article is distributed under the terms of the Creative Commons Attribution 4.0 International License (http:// creativecommons.org/licenses/by/4.0/), which permits unrestricted use, distribution, and reproduction in any medium, provided you give appropriate credit to the original author(s) and the source, provide a link to the Creative Commons license, and indicate if changes were made.
\end{abstract}

S. Pagano

salvo_pagano@hotmail.com

1 Sezione di Medicina Interna e Malattie Metaboliche, Dipartimento di Medicina Interna e Specialistica, DIBIMIS, Università di Palermo, Palermo, Italy

2 Dirigente Medico presso MCAU, ARNAS Civico, Palermo, Italy 


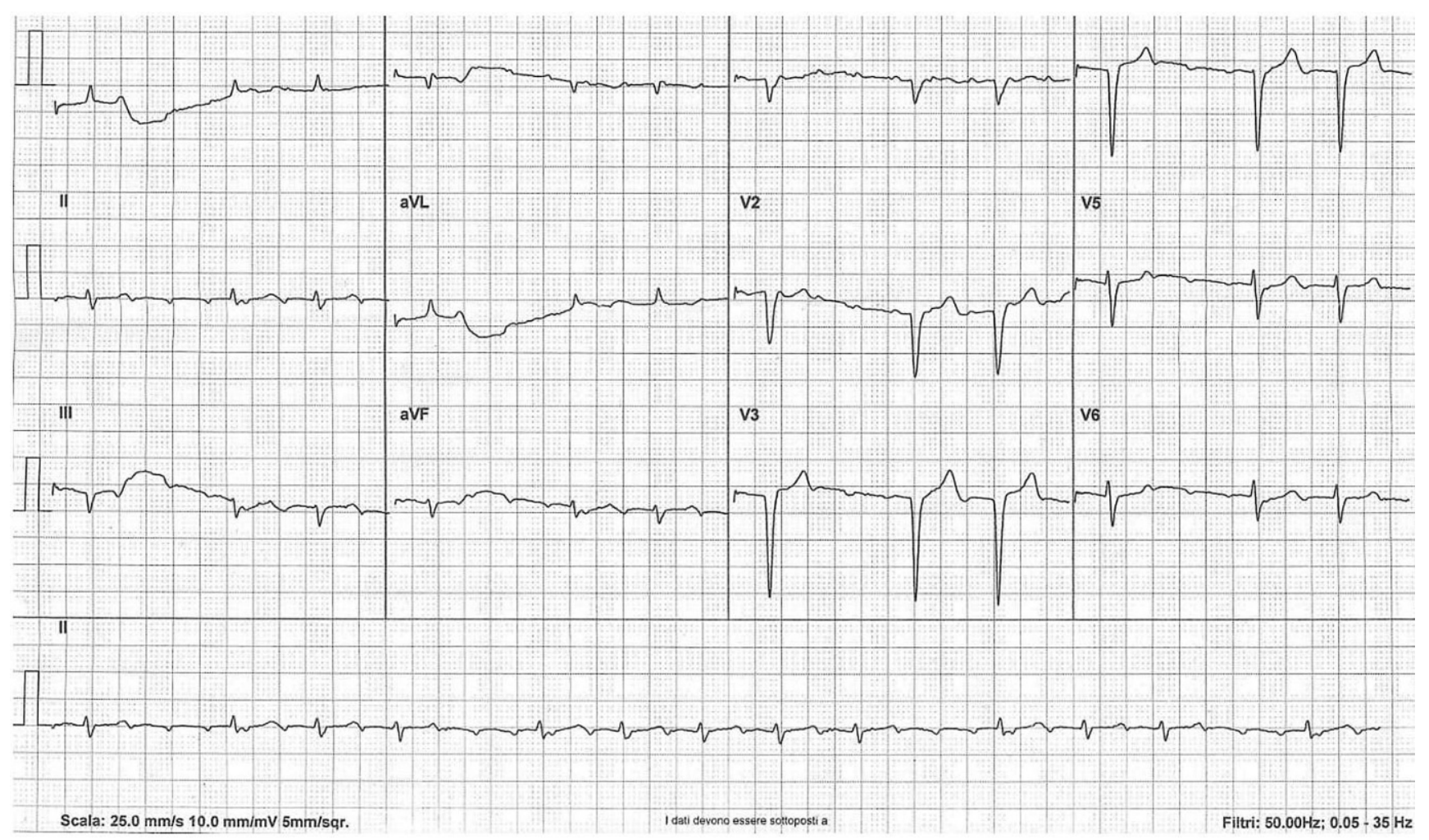

Fig. 1 The irregular atrial tachycardia 